\title{
A multiscale methodology for CFD simulation of catalytic distillation bale packings
}

\author{
Huidian Ding ${ }^{1, ~ *, ~ W e n y u ~ X i a n g ~}{ }^{2,3,4}$, Chunjiang Liu' ${ }^{2,3,4}$ \\ ${ }^{1}$ Research Institute of Petroleum Processing, SINOPEC, Beijing 100083, China \\ ${ }^{2}$ Tianjin University, School of Chemical Engineering and Technology, Tianjin 300072, China \\ ${ }^{3}$ Tianjin University, State Key Laboratory of Chemical Engineering, Tianjin 300072, China \\ ${ }^{4}$ Collaborative Innovation Center of Chemical Science and Engineering (Tianjin), Tianjin 300072, China \\ "Corresponding author: e-mail: ding6389@126.com
}

\begin{abstract}
A multiscale model for simulating the hydrodynamic behavior of catalytic bale packings has been proposed. This model combines computational fluid dynamics (CFD) and macroscopic calculation. At small scale calculation, the CFD model includes 3-D volume-of-fluid (VOF) simulation within representative elementary unit (REU) under unsteady-state conditions. The REU constitutes gauze and catalyst domain, and porous media model is applied. At large scale calculation, a new mechanistic model deduced from the unit network model is employed. Based on liquid split proportion from small scale calculation, liquid distribution of the entire bale packing can be predicted. To evaluate different packing design, three common bale arrangements, i.e. one-bale, nine-bales and seven-bales, are compared. The area-weighted Christiansen uniformity coefficient is introduced to assess the distribution performance. A comparison between simulation and experimental results is made to validate the multiscale model. The present methodology is proved to be effective to analysis and design of catalytic distillation columns.
\end{abstract}

Keywords: multiscale model, CFD, reactive distillation.

\section{INTRODUCTION}

Catalytic distillation integrates catalytic reaction with distillation. In catalytic distillation, the products are separated from the reactant instantly when the reaction proceeds, which promotes the equilibrium to the products. Catalytic distillation has a wide range of application such as esters ${ }^{1-3}$, acetal ${ }^{4}$ and gasoline additive synthesis ${ }^{5-8}$. Catalyst immobilization in a distillation column is one of the technical issues in industrialization. The severe gas-liquid interaction results in poor liquid contact and catalyst loss. These may further lead to catalyst inefficiency, gas-liquid channel blockage and excessive pressure drop. To tackle this issue, the modular catalytic structured packing (MCSP) like bale packing, 10, Katapak $^{11,12}$, and Multipak ${ }^{13,14}$ have been proposed and studied.

The influence of pressure drop, liquid holdup and mean residence time distribution on the performance of MCSP has been investigated by many researchers. Generally, low pressure drop, large liquid holdup and long mean residence time are beneficial for the performance of MCSP. To probe the gas-liquid flow pattern inside MCSP, a visualized approach, X-ray tomography, has been developed, which gives access to local hydrodynamic behavior such as liquid holdup, liquid film thickness and gas-liquid interfacial area ${ }^{15-17}$.

Van Baten et al. ${ }^{18,19}$ employed a CFD model to evaluate the gas phase and liquid phase mass transfer on the criss-crossing structure of Katapak-S. The computational domain contains 16 triangular channels where a single triangular channel is $18 \mathrm{~mm}$ high, $36 \mathrm{~mm}$ wide, and the computational grid consists of 130.000 cells. Due to the favorable gas-liquid interaction inside the packing, the mass transfer coefficient is significantly higher than that of a fully developed flow in a single packed tube. Besides, they ${ }^{20}$ also investigated the radial and axial liquid-phase dispersion in Katapak-S with experiments and CFD simulation. The results showed that Katapak-S has excellent radial dispersion characteristics. Dai et al. ${ }^{21}$ studied the pressure drop and mass transfer of two types of structured catalytic packings. The cold model experimental results showed their superior performance over that of fixed-bed reactors. A 3-D Eulerian multiphase model under steady-state conditions was established to study the separation performance. They discussed geometric configuration to obtain preferred pressure drop and mass transfer coefficients. van Gulijk ${ }^{22}$ examined the effect of hydrodynamics of liquid on the scale up properties by CFD. He found that the radial dispersion coefficient was much higher than that of single phase packed bed flow. Klöker et al. $^{23}$ and Egorov et al. ${ }^{24}$ proposed an innovative method which combines CFD and rate-based approach. Hydrodynamic and mass-transfer correlations were obtained so that the required column profiles can be determined.

Although computers have become increasingly powerful, simulations are quite time consuming when dealing with the multi-phase scenario in the structured packings. The representative elementary units (REU) approach makes it realizable for its advantage of time saving. Larachi and his co-workers ${ }^{25,26}$ developed a meso-microscale predictive approach which consists of five different representative elementary units in corrugated-sheet structured packings. Various kinds of packings were calculated based on the REU method, which remarkably reduced the computational domain. Sun et al. ${ }^{27}$ proposed a multiscale approach combined CFD and macroscopic calculation. On the basis of REU, hydrodynamic behavior of the structured packing was predicted by the 3 -D volume-of-fluid model. Then they applied the unit network model in large scale calculation. The model was validated by experimental results, which has been proven to be prospective in the column design.

It is rather difficult to simulate each catalyst particle inside the packing. However, the porous media model is suitable in this case. Atta et al. ${ }^{28}$ presented a two-phase Eulerian model based on the porous media concept to 
investigate liquid mal-distribution in trickle-bed reactor. They divided the computational domain into distributor section and packed bed section, and the results of distributor were used as inlet conditions of the packed bed. The model was proved to be advantageous in gas-liquid interaction terms.

This work targets at simulation and experimental validation of industrial-scale bale packings, which are less reported in relative publications. Afterwards, the simulation of the bale packing at large scale with specific flow pattern in each area is investigated. This predictive method provides relatively credible but safer and more economic liquid behavior results compared to the existing works ${ }^{15-17}$.

\section{CALCULATION STRATEGY}

\section{Small scale}

The VOF model is employed to depict the gas-liquid flow while considering the packing geometry. The VOF model can simulate the gas-liquid flow by solving momentum equations and it is effective to track the gas-liquid interface.

For the liquid phase in this work, the volume fraction equation is

$\frac{1}{\rho_{L}}\left[\frac{\partial}{\partial t}\left(\alpha_{L} \rho_{L}\right)+\nabla \cdot\left(\alpha_{L} \rho_{L} u_{L}\right)=S_{\alpha_{L}}+\dot{m}_{\mathrm{GL}}-\dot{m}_{\mathrm{LG}}\right]$

In each cell, gas and liquid volume fraction $\alpha_{G}, \alpha_{L}$ is normalized to 1 :

$\alpha_{G}+\alpha_{L}=1$

The momentum transport equation is

$\frac{\partial}{\partial t}(\rho u)+\nabla \cdot(\rho \mathbf{u u})=-\nabla P+\nabla \cdot\left[\mu\left(\nabla \mathbf{u}+\nabla \mathbf{u}^{T}\right)\right]+\rho \mathbf{g}+\mathbf{F}$

For the fluid physical properties, they are volume fraction weighted. The surface force is modeled and incorporated into the volume force $\mathbf{F}$ in Eq. $(3)^{\mathbf{2 9}}$. Sun et al. $^{27}$ discussed the effect of surface tension. Average density $\varrho$ and viscosity $\mu$ are given as

$\rho=\alpha_{\mathrm{L}} \rho_{\mathrm{L}}+\left(1-\alpha_{\mathrm{L}}\right) \rho_{\mathrm{G}}$

$\mu=\alpha_{\mathrm{L}} \mu_{\mathrm{L}}+\left(1-\alpha_{\mathrm{L}}\right) \mu_{\mathrm{G}}$

The standard $k-\omega$ model predicts more accurately at low-Reynolds number flows. Hosseini et al. ${ }^{\mathbf{3 0}}$ compared the experimental data of pressure drop with calculated results using the laminar model and different turbulence models like standard $k-\omega$ model, RNG- $k-\varepsilon$ model and $k-\varepsilon$ model. The standard $k-\omega$ model fits the experimental results with negligible discrepancies and it is used as a prior turbulence model in the present work accordingly.

The turbulence kinetic energy $k$ and the specific dissipation rate $\omega(=k / \varepsilon)$ equations are

$\frac{\partial}{\partial t}(\rho k)+\frac{\partial}{\partial x_{i}}\left(\rho k u_{i}\right)=\frac{\partial}{\partial x_{j}}\left(\Gamma_{k} \frac{\partial k}{\partial x_{j}}\right)+G_{k}-Y_{k}+S_{k}$

$\frac{\partial}{\partial t}(\rho \omega)+\frac{\partial}{\partial x_{i}}\left(\rho \omega u_{i}\right)=\frac{\partial}{\partial x_{j}}\left(\Gamma_{\omega} \frac{\partial \omega}{\partial x_{j}}\right)+G_{\omega}-Y_{\omega}+S_{\omega}$

Similar to common corrugated packing, bale packing is composed by numerous repeated cylindroid-like structures with analogous boundary conditions. The bale packing has a few fiber glass bags which are filled with spherical catalyst. The bags are rolled up with stainless-steel gauze. The schematic diagram of bale packing and representative elementary unit is shown in Figure 1. An elementary unit includes one catalyst domain and two gauze domains as shown in Figure 1(b). The catalyst domain is in the center and it is consisted of three equivalent units. The boundary conditions of faces between gauze and catalyst zone have been set as "Interface", which allows liquid flows through. Others are the default value "wall".

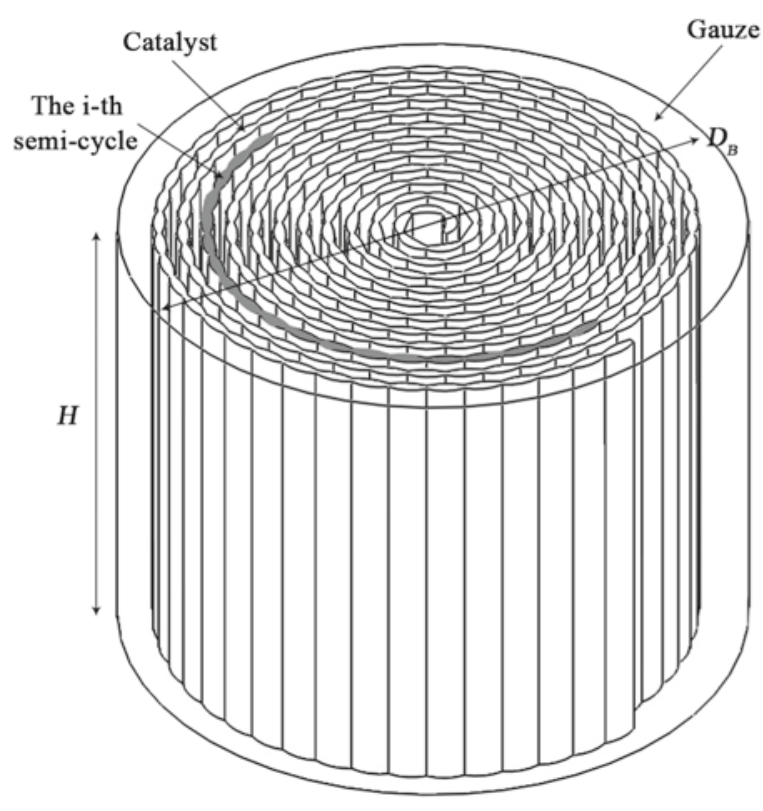

(a)

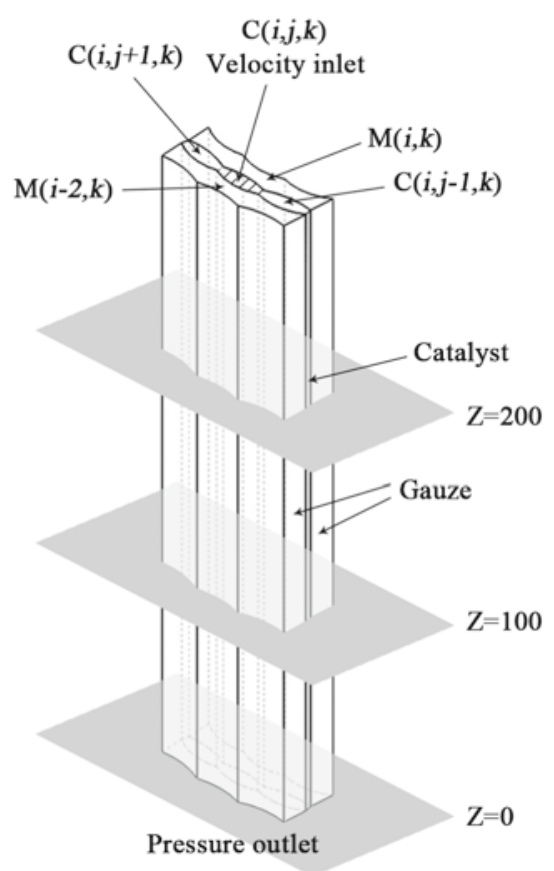

(b)

Figure 1. Bale packing (a) and a representative elementary unit (b) 
Technically, each catalyst particle should be modeled and the contact angle of liquid at catalyst surface should be considered. Sun et al. ${ }^{27}$ compared theoretical least contact angle $0^{\circ}$ with water-packing contact angle $57^{\circ}$. The influence of contact angle is small. Liquid split fraction varies with slightly difference. In this work however, the quantity of catalyst particle could be millions. The geometry building and meshing procedure is tedious and error prone. The porous media model is introduced to simulate the gauze and catalyst domain. In this case, liquid flows through different porous media and thus modeling results can be obtained without considering liquid-solid contact angle.

The porous media model built in Fluent has been applied to interpret flow behavior including the packed bed, tube tanks and perforated plates. An additional momentum loss is added to the body force $\mathbf{F}$ in the momentum Equation (3):

$S_{i}=-\left(\sum_{j=1}^{3} D_{i j} \mu v_{j}+\sum_{j=1}^{3} C_{i j} \frac{1}{2} \rho|v| v_{j}\right)$

The catalyst and gauze in the bale packing can be treated as porous media which possess different permeability. The catalyst as a packed section is modeled using permeability loss coefficient $\alpha$ and inertial loss coefficient $C_{2}$ :

$\frac{|\Delta p|}{L}=\frac{\mu}{\alpha} v_{\infty}+2 C_{2} v_{\infty}^{2}$

with

$\alpha=\frac{D_{p}^{2}}{150} \frac{\varepsilon^{3}}{(1-\varepsilon)^{2}}$

$C_{2}=\frac{3.5}{D_{p}} \frac{(1-\varepsilon)}{\varepsilon^{3}}$

The gauze is considered as fibrous porous media and $\alpha^{31}$ can be determined as

$\alpha=B a^{2}$

Where $\mathrm{D}_{\mathrm{p}}$ is equivalent diameter, $B$ is the dimensionless permeability and $a$ is the fiber diameter. The details of fibrous porous media permeability can be found in Jackson's work ${ }^{31}$. When using these above modeling equations, the adopted coefficients are listed in Table 1.

To investigate the liquid flow pattern within the center unit, a uniform flow status is assumed at the initial state. The structure parameters of bale packing applied in this work are listed in Table 2.

It is known that 2-D (two-dimensional) simulation saves time and reasonable results can be obtained, but 3D simulation is able to discover the non-uniformity and development in the omitted dimension. For the present three-dimensional unsteady two-phase flow simulation, after a compromise analysis between grid independency and required computation time, the computational domain is determined to be about 670,000 hexahedral/
Table 2. Parameters of bale packing

\begin{tabular}{|l|c|c|}
\hline & Unit & Value \\
\hline Bale packing diameter, $D_{\mathrm{B}}$ & $\mathrm{mm}$ & 400 \\
\hline Bale packing height, $H$ & $\mathrm{~mm}$ & 300 \\
\hline Catalyst diameter, $D_{p}$ & $\mathrm{~mm}$ & 0.8 \\
\hline Void fraction, $\varepsilon$ & - & 0.883 \\
\hline Specific surface area, $a_{p}$ & $\mathrm{~m}^{2} \cdot \mathrm{m}^{-3}$ & 100 \\
\hline
\end{tabular}

wedged cells (see Figs. 2(a) and 2(b)). Turbulence model utilized is the standard $k$ - $\omega$ model and multiphase model of VOF model is introduced. Model constants in the $k-\omega$ model are set to be default and $k-\omega$ options select shear flow correlations. VOF scheme is explicit and courant number is set to be 0.25 . The time step size is regulated by global Courant number which has been set to 2 . PISO (pressure-implicit with splitting of operators) is chosen as the pressure-velocity coupling strategy. The momentum discretization method is PRESTO (pressure staggering option) and first-order upwind scheme. Air-water system is used so that the simulation can be verified by our previous cold model experiments ${ }^{\mathbf{1 0}}$. The properties are set as constant at $15^{\circ} \mathrm{C}$. The continuity residual is set to $10^{-3}$ and other residuals are set to $10^{-4}$. Two servers, each of which equipped four AMD Opteron Processor 6128 CPUs with 32 GB of RAM, perform these simulations. For the model in Figure 1b, liquid enters only in the middle unit and the liquid spray density from 10 to 30 $\mathrm{m}^{3} \cdot \mathrm{m}^{-2} \cdot \mathrm{h}^{-1}$ is applied, which is common in practical operation of catalytic distillation columns. Gas velocity is set to be 0 as the gas phase has little effect on the liquid holdup before the loading point ${ }^{10,32,33}$. The flow pattern reaches its dynamic equilibrium after a long period of time (three times or even more time that liquid flows through the packing). The relative difference of mass flow between liquid inlet and outlet is less than $1 \%$ and the continuity residual drops below the criterion.

\section{Macro scale}

The small scale calculation gives the proportion of liquid flowing to the left unit, right unit, front gauze and back gauze. Pressure drop, liquid holdup and gas-liquid flow behavior of the local units can be obtained accordingly. To get the liquid distribution of the whole bale packing with CFD method, the mesh could reach about 50,000,000 cells, which is far beyond the capability of ordinary servers. In contrast, using macro scale calculation with the REU model, the computing load can be significantly reduced. On the basis of the liquid splitting rules, the macro scale calculation provides liquid flow pattern of the whole bale packing, which is crucial to the design of a catalytic distillation column. Figure 3 gives the general idea of the multiscale method.

The macro scale calculation of bale packing is a new mechanistic model which is deduced from a unit network model $^{27}$. The model is based on following assumptions:

a) Liquid in one unit can be divided into several different independent parts.

b) The structural difference among units is minimal and liquid flow pattern of each unit is the same.

Table 1. Fitting parameters used in the porous model

\begin{tabular}{|l|c|c|c|}
\hline Porous zone & $\begin{array}{c}\text { Viscous resistance } \\
1 / \alpha\left[\mathrm{m}^{-2}\right]\end{array}$ & Inertial resistance $C_{2}\left[\mathrm{~m}^{-1}\right]$ & Void fraction, $\varepsilon$ \\
\hline Gauze & $2.624 \times 10^{6}$ & 78 & 0.990 \\
\hline Catalyst & $3.310 \times 10^{9}$ & $9.085 \times 10^{4}$ & 0.320 \\
\hline
\end{tabular}




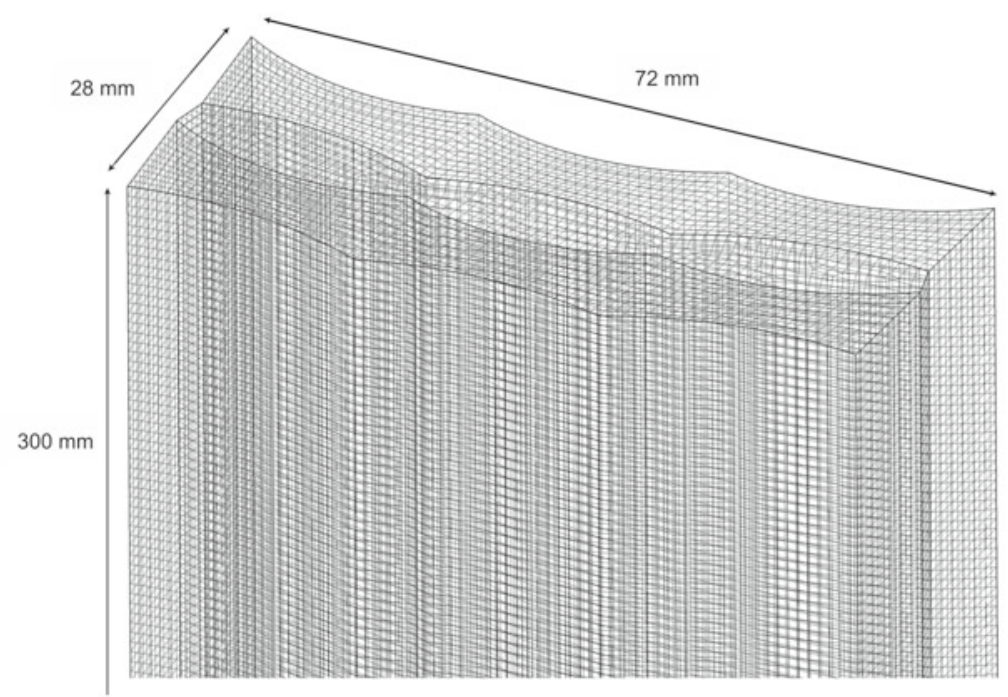

(a)

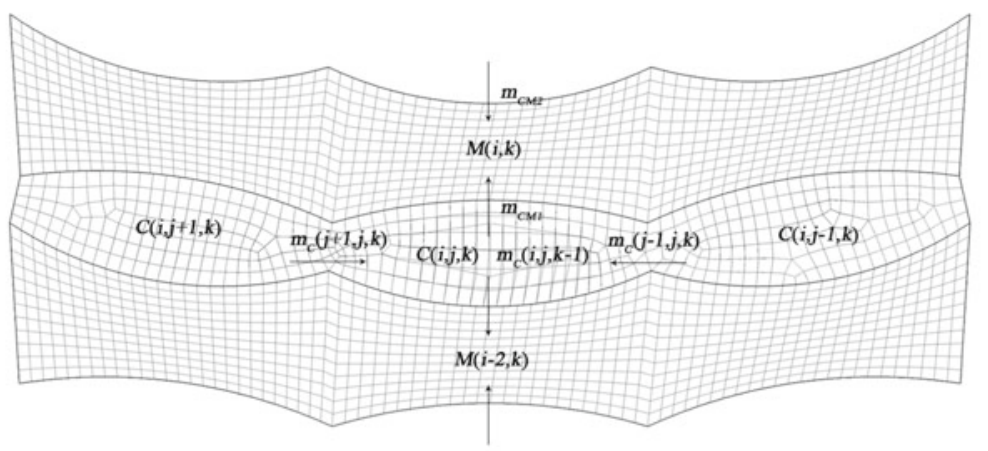

(b)

Figure 2. Computational grid (a) and law (b) of the representative elemental unit

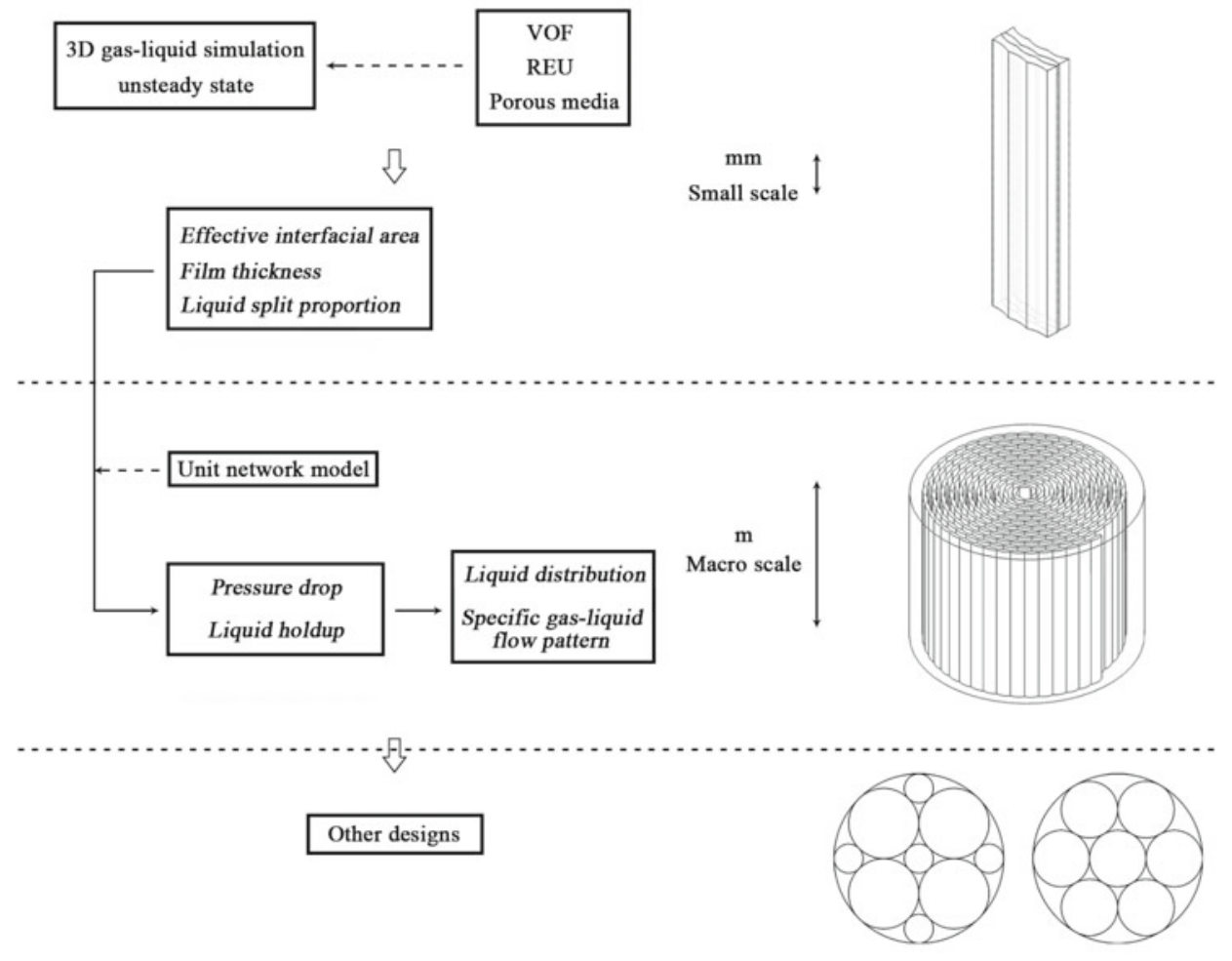

Figure 3. General strategy of the multiscale method

c) The influence of the fiber glass can be neglected. As demonstrated in Figure 1b, the column section is divided into $i$ bale layers. The $i$-th layer has $j$ units. Vertically there are defined $1,2 \ldots k, k+1$ cells from top to bottom. Each unit is clockwise named as $C(i, j, k)$.
In this study, $i=1-22$ and $j \leq 24-i$. The gauze is studied as each semi-cycle named $M(i, k)$ rather than one single unit. $M(i, k)$ locates between the $i$-th and $(i+2)$-th catalyst semi-cycle. 
To illustrate the liquid behavior in a selected unit, three horizontal parallel planes have been created at different $z$. Liquid spray density in a cross section is calculated by the following equations:

$$
S_{c}(i, j, k)=\frac{m_{c}(i, j, k-1)+m_{c}(j-1, j, k)+m_{c}(j+1, j, k)}{\rho A_{c}(i, j, k)}
$$

$S_{M}(i, k)=\frac{\sum_{1}^{j}\left(m_{C M 1}+m_{C M 2}\right)}{\rho A_{M}(i, k)}$

where $S_{\mathrm{C}}(i, j, k)$ and $S_{\mathrm{M}}(i, k)$ are spray density of unit $C(i, j, k)$ and gauze $M(i, k)$ respectively. $\mathrm{Q}$ is liquid density. $A_{C}(i, j, k)$ and $A_{M}(i, k)$ are area of unit $C(i, j, k)$ and gauze $M(i, k)$. The downstream part of the liquid mass flow into unit $C(i, j, k)$ is $m_{C}(i, j, k-1)$. Since the catalyst layer is porous, liquid flows to both left and right side. $m_{C}(j-1, j, k)$ and $m_{C}(j+1, j, k)$ represent mass flow from unit $C(i, j-1, k)$ to $C(i, j, k)$ and mass flow from unit $C(i, j+1, k)$ to $C(i, j, k)$ respectively. Besides, liquid also flows from catalyst region to the gauze part. Mass flow from unit $C(i, j, k)$ and $C(i+2, j, k)$ to gauze $M(i, k)$ are defined as $m_{\mathrm{CM} 1}$ and $m_{\mathrm{CM} 2}$. All those liquid split parameters are deduced from small scale calculation of the simulation results. The details of how the liquid in the unit $C(i, j, k)$ and gauze $M(i, k)$ flow into neighboring regions is revealed in Figure 2(b). Equations. (13) and (14) have considered different units contribute to liquid flow in unit $C(i, j, k)$. Thus the liquid distribution can be calculated by the unit network model.

\section{RESULTS AND DISCUSSIONS}

\section{Dry pressure drop}

The macro model was applied to compute the dry pressure drop through the column packed with catalyst bales as designated by Table 2 and Figure 1. Pressure drop is a fundamental factor when evaluating the packing performance. The lower the pressure drop is, the higher capacity the catalytic distillation column would possess. Pressure drop of dry packing indicates the minimal situation at the same air velocity, which means irrigated pressure drop increases as a benchmark. Small scale simulation has calculated the pressure drop of the selected unit in Figure 1(b). Due to the structural similarity in the bale packing, the overall pressure drop (macro scale) is the same as the unit (small scale). As presented in Figure 4, the curve sees a good fitting at the minor $F$ factor $\left(\mathrm{F}=\mathrm{v}^{*} \mathrm{Q}^{0.5}\right.$, product of gas velocity $\mathrm{v}$ and square root of gas density $\mathrm{Q}$ ) and a slight deviation at the intense area. The experimental data come from our previous work ${ }^{\mathbf{1 0}}$. Overall, the CFD method predicts the dry pressure drop rather well.

\section{Liquid holdup}

For the conventional distillation, engineers usually prefer packing which holds less liquid holdup. Quite different, however, liquid holdup plays a significant role in the catalytic distillation procedure. In either liquid-liquid reaction like MTBE synthesis or gas-liquid reaction like alkylation process, chemical reactions proceed in the liquid phase and it takes time to complete. Therefore,

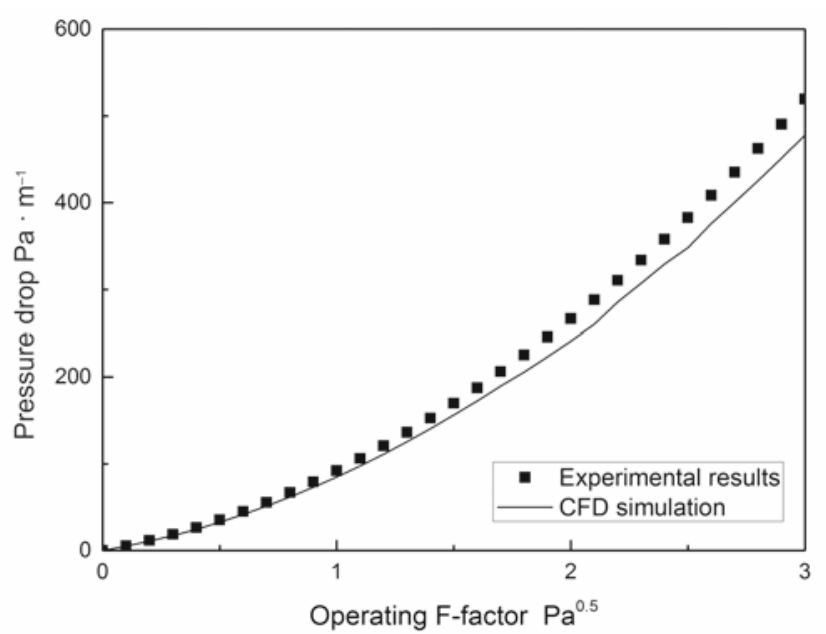

Figure 4. Dry pressure drop of experimental results and CFD simulation

higher liquid holdup means longer residence time, which contributes to higher productivity.

The calculation of liquid holdup $h_{\mathrm{L}}$ is by

$h_{L}=\frac{a_{e}}{a_{p}} a_{p} \delta_{L}$

where $a_{\mathrm{e}}$ is the effective interfacial area, $\delta_{\mathrm{L}}$ is liquid film thickness.

Prediction of the effective wetting ratio $a_{\mathrm{e}} / a_{\mathrm{p}}$ has been studied by Rocha et al. ${ }^{34}$, Brito et al. ${ }^{35}$, Brunazzi et al. ${ }^{36}$, Billet and Schultes ${ }^{37}$, Olujić et al. ${ }^{38}$ and so on. They considered many specific conditions such as packing structure and operating condition. The results fit well in certain kinds of packings. In this work, first we export the specific liquid distribution (gas-liquid fraction contour) as a few individual graphic files for different gas/liquid loading with the help of Tecplot 360 . Then we use image processing software to analyze these files' each pixel and sum up all the results. The effective wetting ratio can be calculated directly. Contrast of different models with the present CFD model has been depicted in Figure 5. It can be found that value of $a_{e} / a_{p}$ increases along the increase of spray density with the exception of Brunazzi model. The Brito model predicts $a_{e} / a_{p}$ higher than 1 . The reason is that it combines the rivulet flow, fluctuation on the free surface, film tear, droplet from the gas blow,

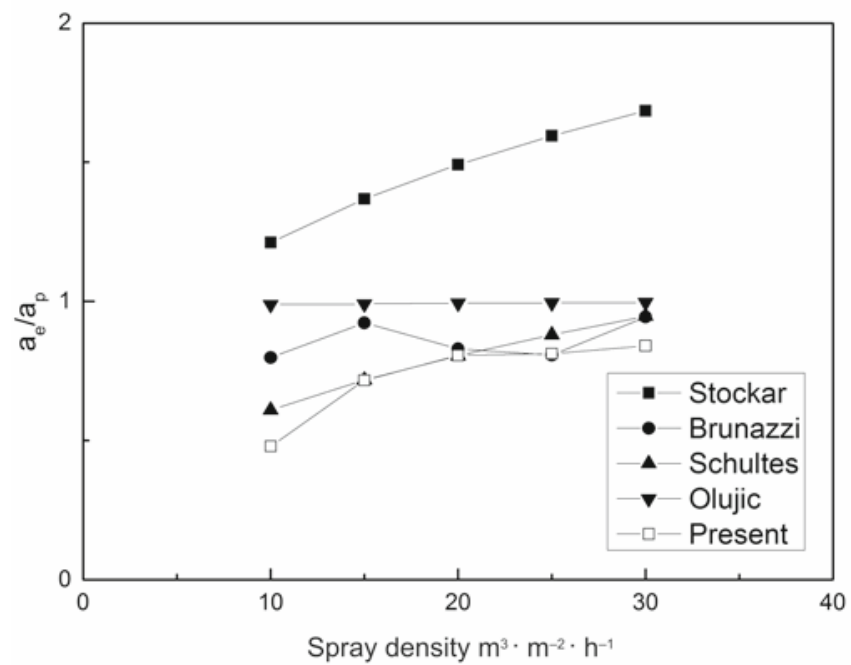

Figure 5. Contrast of effective wetting ratio calculated by different models 
effusion between the packings and column internals. Olujić mode $\mathrm{l}^{39}$ aims at Montz-pak, whose prediction is close to 1 . The Billet model ${ }^{38}$, which is deduced from numerous kinds of packings include both random packing and structured packing, is the most similar to the present CFD model. As we can see, although researchers have proposed various models to calculate the effective wetting ratio, none of them is universal. If the CFD model is proven to be reliable, it is more convenient to predict the effective wetting ratio using Fluent.

In many researches, the liquid film thickness $\delta_{\mathrm{L}}$ is estimated as $\delta_{L}=\left[3 \mu_{L} q /\left(\varrho_{G} g \cos \theta\right)\right]^{0.333}$. But it is not appropriate in this work as the liquid flows in both catalyst and gauze. As the liquid film is three-dimensional, it is hard to determine the thickness conveniently and precisely. Here we propose a direct measurement procedure that creates a series of parallel cross sections in Tecplot 360 with data obtained from CFD. Then each cross section possesses a two-dimensional film. By averaging all the thickness of liquid film, the overall liquid film thickness $\delta_{\mathrm{L}}$ can be obtained.

It can be observed in Figure 6 that the liquid holdup predicted by the present model agrees well with experimental data. The good agreement suggests a high level of reliability of the present CFD model, which lays a solid foundation for subsequent studies on the liquid distribution and optimum design.

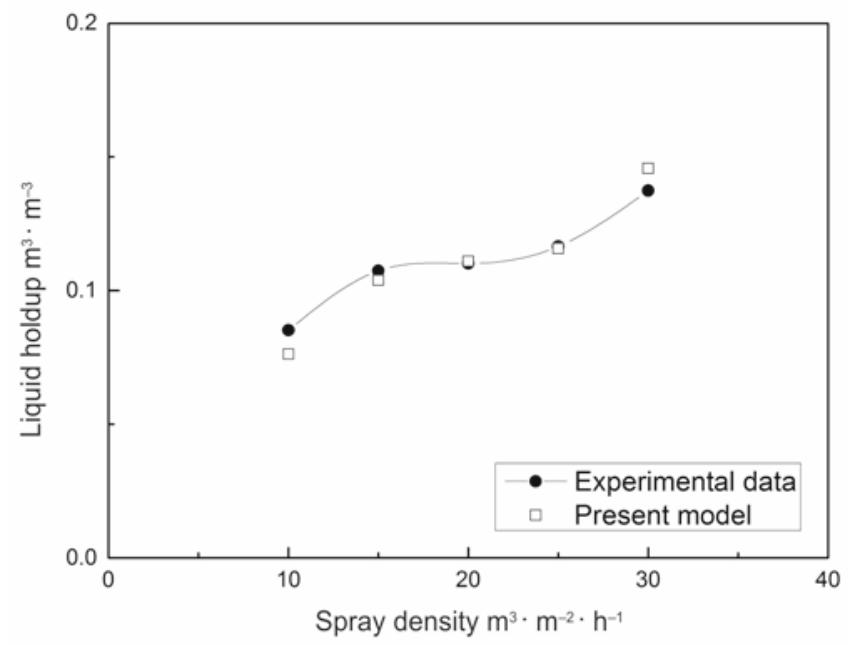

Figure 6. Liquid holdup obtained from experiments and present model

\section{Liquid distribution in the column}

A variety of methods ${ }^{39,40}$ are available for the evaluation of the coefficient of uniformity. Area-weighted Christiansen uniformity coefficient $C_{\mathrm{UHH}}$ has been applied in many situations including the Chinese National Stan$\operatorname{dard}^{41}$. In the present study, we have proposed similar evaluation index:

$C_{U H H}=\left(1-\frac{\sum_{i=1}^{n} A_{i}\left|S_{D i}-\overline{S_{D}}\right|}{\sum_{i=1}^{n} A_{i} S_{D i}}\right) \times 100 \%$

In Eq. (16), $A_{i}$ and $S_{\mathrm{D} i}$ represents area and spray density of the $i$-th point. $S_{D}$ means average spray density.
The larger value of $C_{\mathrm{UHH}}$ is preferred as it represents better distribution quality.

The liquid distribution results $\left(\mathrm{m}^{3} \cdot \mathrm{m}^{-2} \cdot \mathrm{h}^{-1}\right)$ on different plains are shown in Figure 7. The packing diameter is $400 \mathrm{~mm}$ and the height is $300 \mathrm{~mm}$. The water inlet is uniformly distributed and the spray density is $S=15 \mathrm{~m}^{3} \cdot \mathrm{m}^{-2} \cdot \mathrm{h}^{-1}$. It can be seen from Figure 7 that whether the liquid distributes evenly or not depends largely on the initial distribution.

Figures 7(a) to 7(c) are the cases of uniform feeding. Liquid distributes rather well after $300 \mathrm{~mm}$ height of flowing down. However, in the case of four-point feeding (see Figs. 7(d) to 7(f)), most part of the packing remains unwetted, and the liquid distribution changes little with respect to the original state. In Figsure $7(\mathrm{~g})$ to 7(i), we assume that there is less liquid irrigation in the lower right of the packing and a larger part in the upper left section. Although liquid has flowed down for $300 \mathrm{~mm}$, it is pretty clear that the mal-distribution has not been improved at all, and little liquid flows to the adjacent units.

Figure 8 exhibits the area-weighted Christiansen uniformity coefficient $C_{\mathrm{UHH}}$ on three plains: $Z=0$ $\mathrm{mm}, Z=100 \mathrm{~mm}, Z=200 \mathrm{~mm}$. It is explicit that the curves reach their peaks around the spray density $15 \mathrm{~m}^{3} \cdot \mathrm{m}^{-2} \cdot \mathrm{h}^{-1}$ while the liquid distribution deteriorates afterwards. Due to the considerable longitudinal dispersion ability of bale packing, liquid flow pattern ameliorates when liquid flows down.

\section{Other designs}

The arrangement of the bale packing in this research is one single bale roll in the column. There are other arrangements used in engineering. A four-big-bales and five-small-bales installation method is shown in Figure 9(a). Figure 9(b) depicts a seven-bales approach, where seven same-sized bales are placed closely. Compared with one single bale arrangement, the latter two methods contain a significant part of void volume fraction. Although engineers can rotate the bale arrangement layer by layer by certain angles to avoid liquid short-circuit, the void volume would result in wasted space and decreased liquid uniformity.

The liquid distribution of the three installation approaches are presented in Figure $10(Z=0 \mathrm{~mm})$. Liquid flows much less in the void volume than in the packing and the area of the low liquid flow region expand along the order of one-bale, nine-bales and seven-bales. Some region in the column may never be irrigated in the latter two arrangements. This would create gas-liquid short circuit, channel flow and refracted flow. It risks further back mixing and a remarkable efficiency waste, which is not expected in a catalytic distillation column.

Figure 11 illustrates the area-weighted Christiansen uniformity coefficient $C_{\mathrm{UHH}}$ of the three arrangements $(Z=0 \mathrm{~mm})$. It is found that the distribution quality of one-bale overweighs far more than both the nine-bales and seven-bales. With the spray density increases, $C_{\mathrm{UHH}}$ of present one-bale presents fluctuations with slightly decrease but $C_{\mathrm{UHH}}$ of the nine-bales and seven-bales shows a rapid decline. This indicates that the nine-bales and seven-bales are more sensitive to liquid flow and 

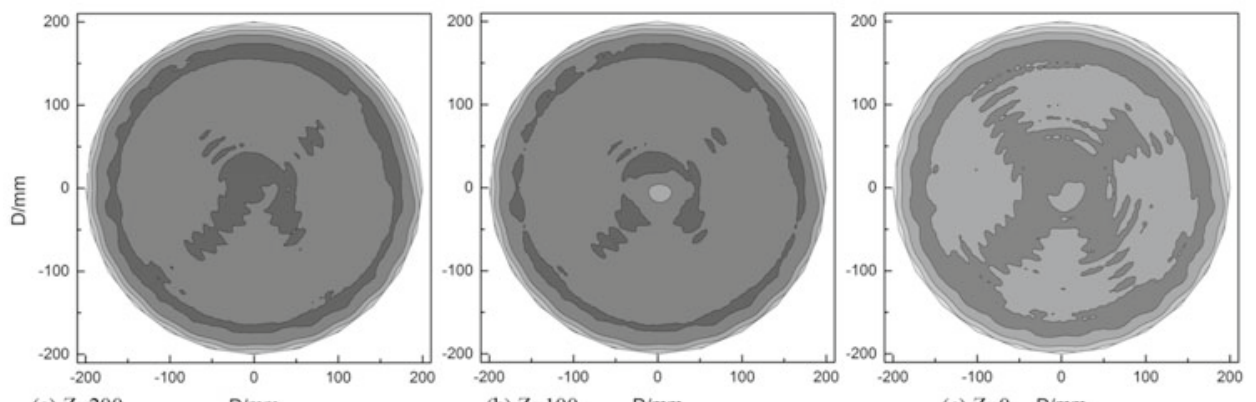

(a) $\mathrm{Z}=\mathbf{2 0 0} \quad \mathrm{D} / \mathrm{mm}$

(b) $Z=100 \quad \mathrm{D} / \mathrm{mm}$

(c) $\mathrm{Z}=0 \quad \mathrm{D} / \mathrm{mm}$
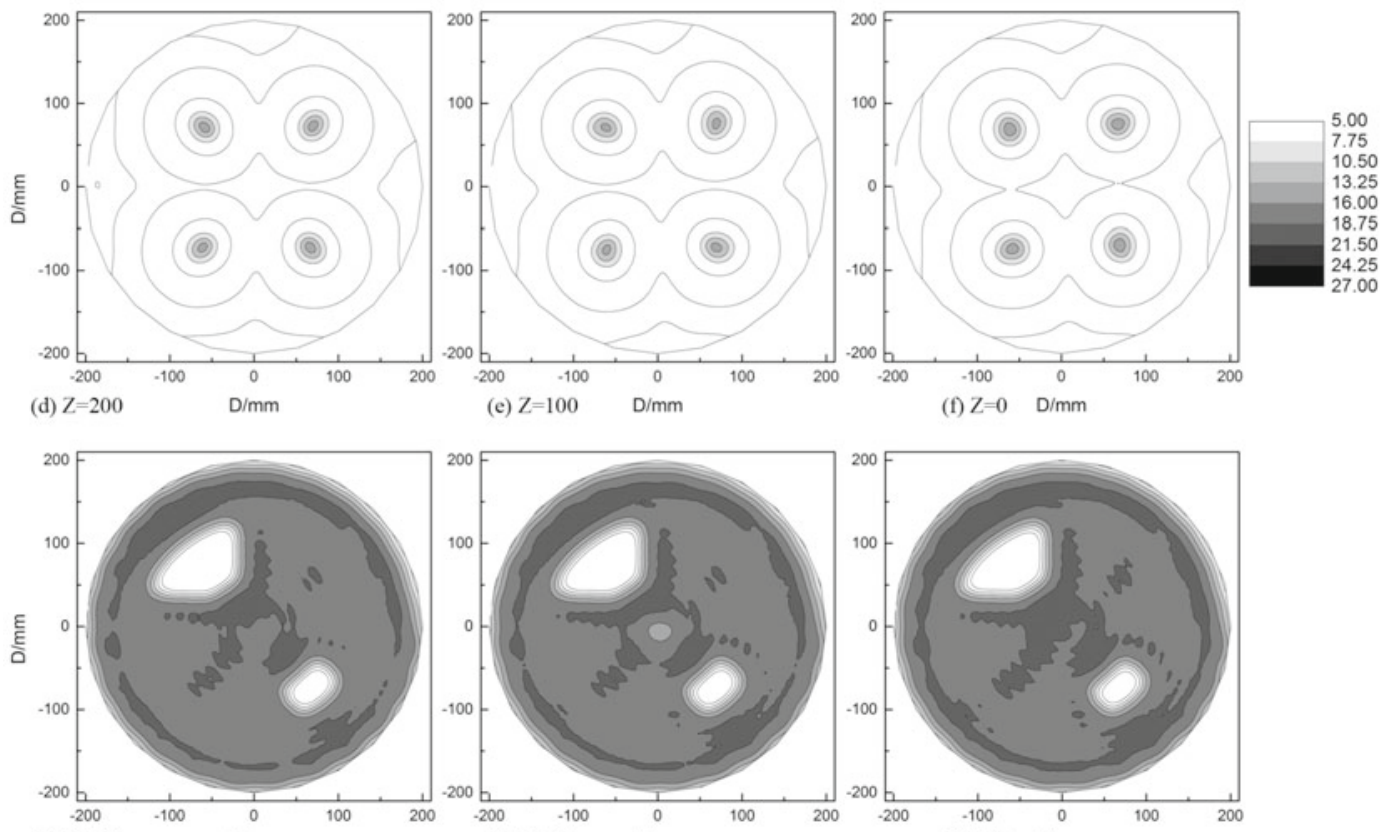

(e) $\mathrm{Z}=100 \quad \mathrm{D} / \mathrm{mm}$

(f) $\mathrm{Z}=0 \quad \mathrm{D} / \mathrm{mm}$
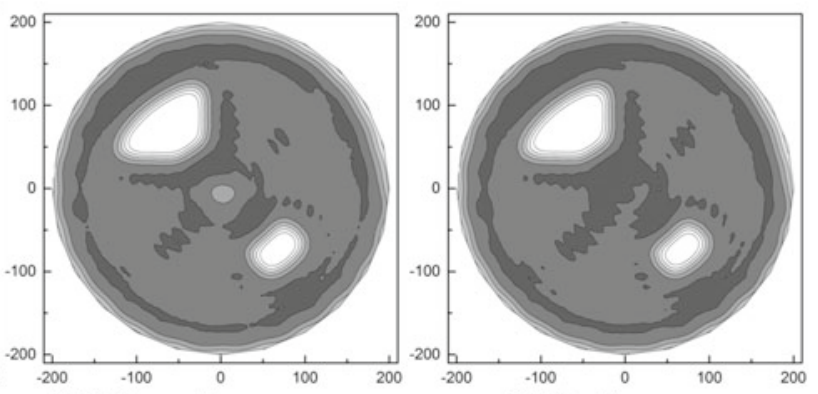

(g) $\mathrm{Z}=\mathbf{2 0 0} \quad \mathrm{D} / \mathrm{mm}$

(h) $\mathrm{Z}=100 \quad \mathrm{D} / \mathrm{mm}$

(i) $\mathrm{Z}=0 \quad \mathrm{D} / \mathrm{mm}$

Figure 7. Liquid distribution results $\left(\mathrm{m}^{3} \cdot \mathrm{m}^{-2} \cdot \mathrm{h}^{-1}\right)$ on different plains. Uniform feeding $(\mathrm{a}, \mathrm{b}, \mathrm{c})$, four-point feeding (d, e, f) and maldistribution $(\mathrm{g}, \mathrm{h}, \mathrm{i})$. Initial spray density $15 \mathrm{~m}^{3} \cdot \mathrm{m}^{-2} \cdot \mathrm{h}^{-1}$

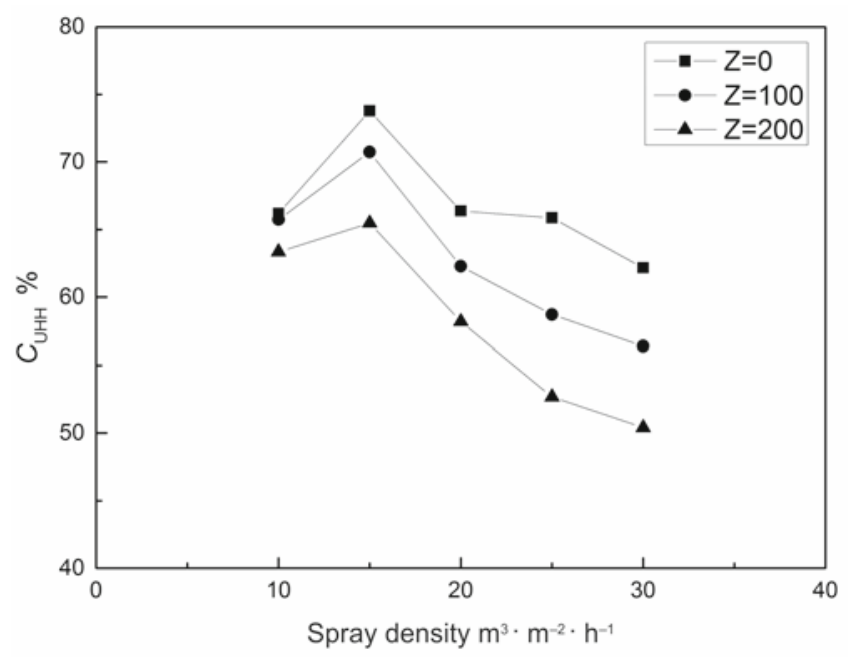

Figure 8. Area-weighted Christiansen uniformity coefficient $C_{\mathrm{UHH}}$ on different plains

thus they are inappropriate candidates for the catalytic distillation.

\section{CONCLUSIONS}

This study proposes a multiscale methodology based on small scale and macro scale calculations. Small scale calculation presents effective interfacial area, film thick-

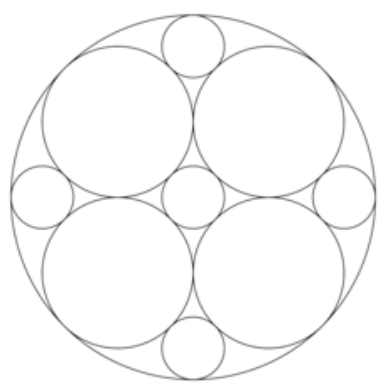

(a)

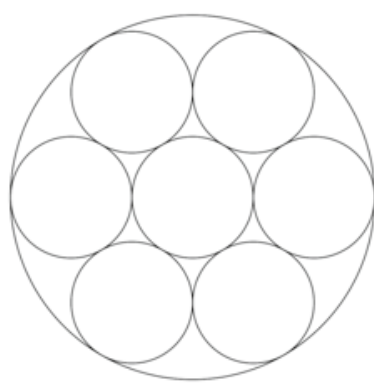

(a)
Figure 9. Other two arrangements of the bale packing

ness and most important liquid split proportion. Based on that, macro scale calculation presents an algorithm which calculates packing pressure drop, liquid holdup and specific gas-liquid flow pattern. The consistency between simulated values and experimental results of dry pressure drop and liquid holdup exhibit the favorable prediction. Bale packing arrangements studies reveal the reliability of one-bale installation. The advantage of the multiscale methodology is that the liquid flow pattern can be predicted freely as long as the geometry is precisely modeled.

Further studies focus on the simulation of the concentration distribution in the packing, where the mass-transfer coefficient in the gauze domain and catalyst domain 


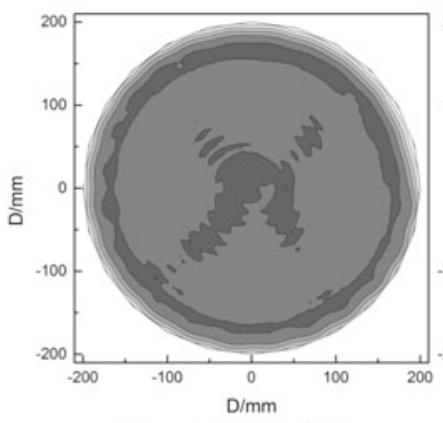

(a) one bale $10 \mathrm{~m}^{3} \cdot \mathrm{m}^{-2} \cdot \mathrm{h}^{4}$

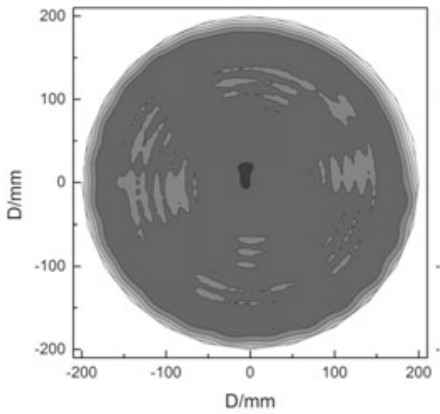

(d) one bale $20 \mathrm{~m}^{3} \cdot \mathrm{m}^{-2} \cdot \mathrm{h}^{-1}$

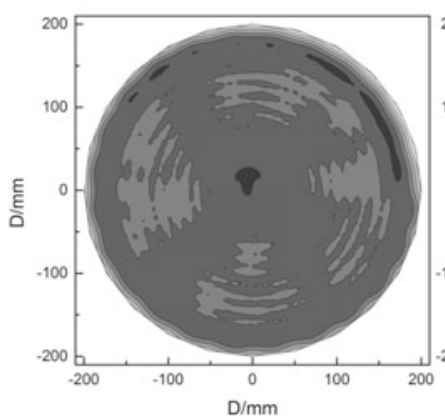

(g) one bale $30 \mathrm{~m}^{3} \cdot \mathrm{m}^{-2} \cdot \mathrm{h}^{-1}$

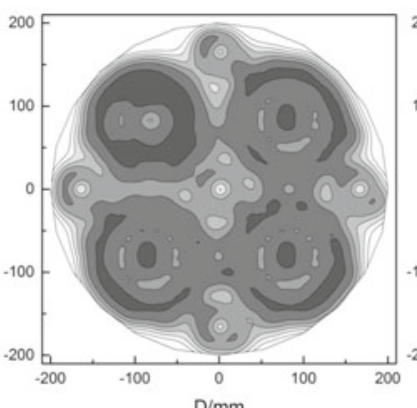

(b) nine bales $10 \mathrm{~m}^{3} \cdot \mathrm{m}^{-2} \cdot \mathrm{h}^{-1}$

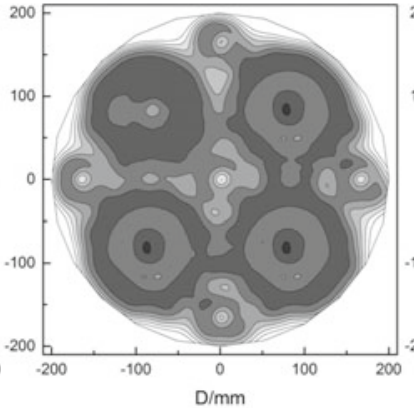

(e) nine bales $20 \mathrm{~m}^{3} \cdot \mathrm{m}^{-2} \cdot \mathrm{h}^{-1}$

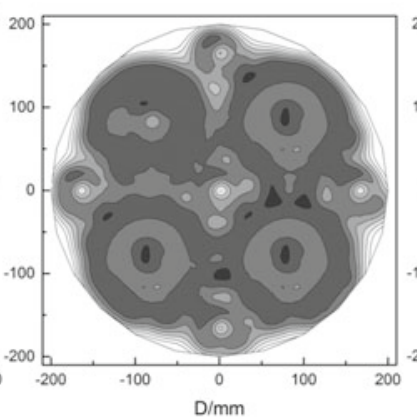

(h) nine bales $30 \mathrm{~m}^{3} \cdot \mathrm{m}^{-2} \cdot \mathrm{h}^{-1}$

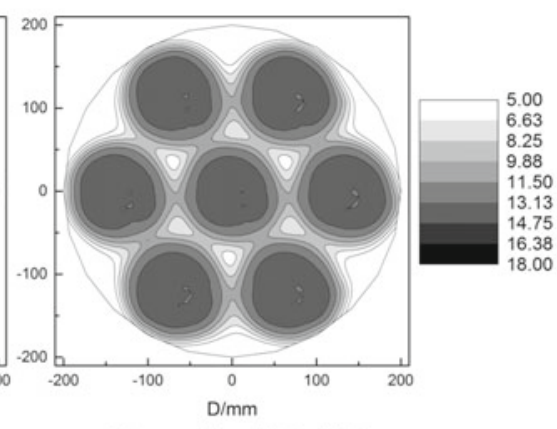

(c) seven bales $10 \mathrm{~m}^{3} \cdot \mathrm{m}^{-2} \cdot \mathrm{h}^{-1}$

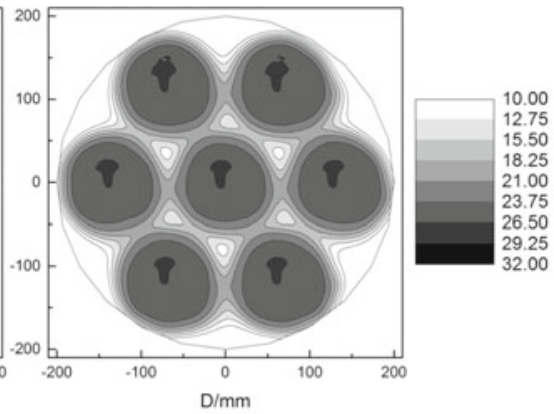

(f) seven bales $20 \mathrm{~m}^{3} \cdot \mathrm{m}^{-2} \cdot \mathrm{h}^{-1}$

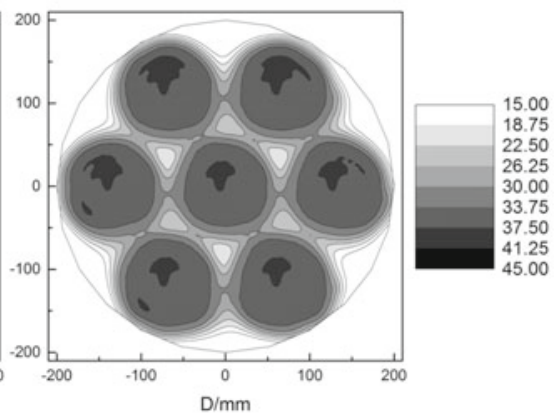

(i) seven bales $30 \mathrm{~m}^{3} \cdot \mathrm{m}^{-2} \cdot \mathrm{h}^{-1}$

Figure 10. Liquid distribution results $\left(\mathrm{m}^{3} \cdot \mathrm{m}^{-2} \cdot \mathrm{h}^{-1}\right)$ of the three arrangements with different spray densities: $(\mathrm{a}, \mathrm{d}, \mathrm{g})$ one-bale, (b, e, h) ninebales, (c, f, i) seven bales

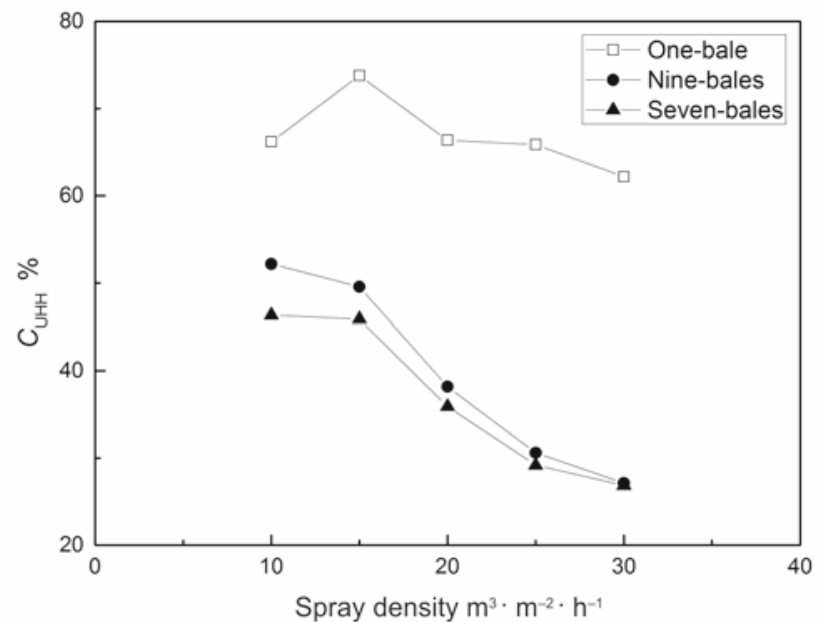

Figure 11. $C_{\mathrm{UHH}}$ contrast of one-bale, nine-bales and seven-bales arrangement

need to be well and accurately assessed. The proposed methodology may be a fundamental way to study the hydrodynamic behavior and mass-transfer performance in a catalytic distillation column.

\section{LITERATURE CITED}

1. Klöker, M., Kenig, E.Y., Górak, A., Markusse, A.P., Kwant, G. \& Moritz, P. (2004). Investigation of different column configurations for the ethyl acetate synthesis via reactive distillation. Chem. Eng. Process. 43, 791-801. DOI: 10.1016/ S0255-2701(03)00084-9.

2. Tian, H., Huang, Z., Qiu, T., Wang, X.D. \& Wu, Y.X. (2012). Reactive distillation for producing n-butyl acetate: Experiment and simulation. Chin. J. Chem. Eng. 20(5), 980-987. DOI: 10.1016/S1004-9541(12)60426-1.

3. Agarwal, M., Singh, K. \& Chaurasia, S.P. (2012). Simulation and sensitivity analysis for biodiesel production in a reactive distillation column. Pol. J. Chem. Technol. 14, 59-65. DOI: 10.2478/v10026-012-0085-2.

4. Zhang, X., Zhang, S. \& Jian, C. (2011). Synthesis of methylal by catalytic distillation. Chem. Eng. Res. Des. 89, 573-580. DOI: 10.1016/j.cherd.2010.09.002.

5. Huang, K. \& Wang, S.J. (2007). Design and control of a methyl tertiary butyl ether (MTBE) decomposition reactive distillation column. Ind. Eng. Chem. Res. 46, 2508-2519. DOI: 10.1021/ie061204c.

6. Vanaki, A. \& Eslamloueyan, R. (2012). Steady-state simulation of a reactive internally heat integrated distillation column (R-HIDiC) for synthesis of tertiary-amyl methyl ether (TAME). Chem. Eng. Process. 52, 21-27. DOI: 10.1016/j.cep.2011.12.005. 
7. Bisowarno, B.H., Tian, Y.C. \& Tadé, M.O. (2004). Application of side reactors on ETBE reactive distillation. Chem. Eng. J. 99, 35-43. DOI: 10.1016/j.cej.2003.09.004.

8. González-Rugerio, C.A., Fuhrmeister, R., Sudhoff, D., Pilarczyk, J. \& Górak, A. (2014). Optimal design of catalytic distillation columns: A case study on synthesis of TAEE. Chem. Eng. Res. Des. 92, 391-404. DOI: 10.1016/j.cherd.2013.08.030.

9. Xu, X., Zhao, Z. \& Tian, S. (1997). Study on catalytic distillation processes part III: Prediction of pressure drop and holdup in catalyst bed. Trans IChemE. 75, 625-629. DOI: $10.1205 / 026387697524155$.

10. Ding, H.D., Xiang, W.Y., Song, N., Liu, C.J. \& Yuan, X.G. (2014). Hydrodynamic behavior and residence time distribution of industrial-scale bale packings. Chem. Eng. Technol. 37(7), 1127-1136. DOI: 10.1002/ceat.201300824.

11. Ratheesh, S. \& Kannan, A. (2004). Holdup and pressure drop studies in structured packings with catalysts. Chem. Eng. J. 104, 45-54. DOI: 10.1016/j.cej.2004.08.004.

12. Behrens, M., Olujić, Ž. \& Jansens, P.J. (2007). Liquid flow behavior in catalyst-containing pockets of modular catalytic structured packing Katapak SP. Ind. Eng. Chem. Res. 46, 3884-3890. DOI: 10.1021/ie060985e.

13. Kołodziej, A., Jaroszyński, M., Schoenmakers, H., Althaus, K., Geißler, E., Üblerb, C. \& Kloeker, M. (2005). Dynamic tracer study of column packings for catalytic distillation. Chem. Eng. Process. 44, 661-670. DOI: 10.1016/j.cep.2004.05.017.

14. Noeres, C., Hoffmann, A. \& Górak, A. (2002). Reactive distillation: Non-ideal flow behaviour of the liquid phase in structured catalytic packings. Chem. Eng. Sci. 57, 1545-1549. DOI: 10.1016/S0009-2509(02)00028-3.

15. Viva, A., Aferka, S., Brunazzi, E., Marchot, P., Crine, M. \& Toye, D. (2011). Processing of X-ray tomographic images: A procedure adapted for the analysis of phase distribution in MellapakPlus 752.Y and Katapak-SP packings. Flow. Meas. Instrum. 22, 279-290. DOI: 10.1016/j.flowmeasinst.2011.03.008.

16. Viva, A., Aferka, S., Toye, D., Marchot, P., Crine, M. \& Brunazzi, E. (2011). Determination of liquid hold-up and flow distribution inside modular catalytic structured packings. Chem. Eng. Res. Des. 89, 1414-1426. DOI: 10.1016/j.cherd.2011.02.009.

17. Aferka, S., Marchot, P., Crine, M. \& Toye, D. (2010). Interfacial area measurement in a catalytic distillation packing using high energy X-ray CT. Chem. Eng. Sci. 65, 511-516. DOI: 10.1016/j.ces.2009.05.048.

18. van Baten, J.M. \& Krishna, R. (2002). Gas and liquid phase mass transfer within KATAPAK-S ${ }^{\circledR}$ structures studied using CFD simulations. Chem. Eng. Sci. 57, 1531-1536. DOI: 10.1016/S0009-2509(02)00026-X.

19. van Baten, J.M. \& Krishna, R. (2001). Liquid-phase mass transfer within KATAPAK-S ${ }^{\circledR}$ structures studied using computational fluid dynamics simulations. Catal. Today. 69, 371-377. DOI: 10.1016/S0920-5861(01)00394-7.

20. van Baten, J.M., Ellenberger J., Krishna R. (2001). Radial and axial dispersion of the liquid phase within a KATAPAK-S ${ }^{\circledR}$ structure: experiments vs. CFD simulations. Chem. Eng. Sci. 56, 813-821. DOI: 10.1016/S0009-2509(00)00293-1.

21. Dai, C., Lei, Z., Li, Q. \& Chen, B. (2012). Pressure drop and mass transfer study in structured catalytic packings. Sep. Purif. Technol. 98, 78-87. DOI: 10.1016/j.seppur.2012.06.035.

22. van Gulijk, C. (1998). Using computational fluid dynamics to calculate transversal dispersion in a structured packed bed. Comput. Chem. Eng. 22, S767-S770. DOI: 10.1016/S00981354(98)00144-6.

23. Klöker, M., Kenig, E.Y. \& Górak, A. (2003). On the development of new column internals for reactive separations via integration of CFD and process simulation. Catal. Today. 79-80, 479-485. DOI: 10.1016/S0920-5861(03)00068-3.

24. Egorov, Y., Menter, F., Klöker, M. \& Kenig, E.Y. (2005). On the combination of CFD and rate-based modeling in the simulation of reactive separation processes. Chem. Eng. Process. 44, 631-644. DOI: 10.1016/j.cep.2003.10.011.
25. Petre, C.F., Larachi, F., Iliuta, I. \& Grandjean, B.P.A. (2003). Pressure drop through structured packings: Breakdown into the contributing mechanisms by CFD modeling. Chem. Eng. Sci. 58, 163-177. DOI: 10.1016/S0009-2509(02)00473-6.

26. Larachi, F., Petre, C.F., Iliuta, I. \& Grandjean, B.P.A. (2003). Tailoring the pressure drop of structured packings through CFD simulations. Chem. Eng. Process. 42, 535-541. DOI: 10.1016/S0255-2701(02)00073-9.

27. Sun, B., He, L., Liu, B.T., Gu, F., Liu, C.J. (2013). A new multiscale model based on CFD and macroscopic calculation for corrugated structured packing column. AIChE. J. 59, 3119-3130. DOI: 10.1002/aic.14082.

28. Atta, A., Roy, S., Nigam, K.D.P. (2007). Investigation of liquid maldistribution in trickle-bed reactors using porous media concept in CFD. Chem. Eng. Sci. 62, 7033-7044. DOI: 10.1016/j.ces.2007.07.069.

29. Fluent Inc., FLUENT 6.3 Documentation, ANSYS Inc., USA, 2006[2014-05-15], http://aerojet.engr.ucdavis.edu/ fluenthelp/html/ug/node1.htm

30. Hosseini, S.H., Shojaee, S., Ahmadi, G. \& Zivdar, M. (2012). Computational fluid dynamics studies of dry and wet pressure drops in structured packings. J. Ind. Eng. Chem. 18, 1465-1473.

31. Jackson, G.W. \& James, D.F. (1986). The permeability of fibrous porous media. Can. J. Chem. Eng. 64, 364-374. DOI: 10.1002/cjce.5450640302.

32. Caetano, M.G., González, J.C. \& Solari, R.B. (2004). Flowdynamic modeling of bale-type catalytic distillation packings. Sep. Sci. Tech. 39, 855-877. DOI: 10.1081/SS-120028450.

33. Akbarnejad, M.M., Safekordi, A.A. \& Zarrinpashne, S. (2000). A study on the capacity of reactive distillation bale packings: Experimental measurements, evaluation of the existing models, and preparation of a new model. Ind. Eng. Chem. Res. 39, 3051-3058. DOI: 10.1021/ie9904706.

34. Rocha, J.A., Bravo, J.L. \& Fair, J.R. (1996). Distillation columns containing structured packings: A comprehensive model for their performance. 2.mass-transfer model. Ind. Eng. Chem. Res. 35, 1660-1667.

35. de Brito, M.H., von Stockar, U., Bangerter, A.M., Bomio, P. \& Laso, M. (1994). Effective mass-transfer area in a pilot plant column equipped with structured packings and with ceramic rings. Ind. Eng. Chem. Res. 33, 647-656. DOI: 10.1021/ie00027a023.

36. Brunazzi, E., Nardini, G., Paglianti, A. \& Petarca, L. (1995). Interfacial area of mellapak packing: absorption of 1,1,1-trichloroethane by genosorb 300. Chem. Eng. Technol. 18, 248-255. DOI: 10.1002/ceat.270180405.

37. Billet, R. \& Schultes, M. (1995). Fluid dynamics and mass transfer in the total capacity range of packed columns up the flood point. Chem. Eng. Technol. 18, 371-379. DOI: 10.1002/ceat.270180602.

38. Olujić, Ž., Kamerbeek, A.B. \& de Graauw, J. (1999). A corrugation geometry based model for efficiency of structured distillation packing. Chem. Eng. Process. 38, 683-695. DOI: 10.1016/S0255-2701(99)00068-9.

39. Hoek, P.J., Wessinlingh, J.A. \& Zuiderweg, F.J. (1986). Small scale and large scale liquid mal-distribution in packed columns. Chem. Eng. Res. Des. 64, 431-449.

40. Christiansen, J.E. (1948). Irrigation by Sprinkling, University of California Press, USA.

41. Chinese National Standard. GB50085-2007T. 